\title{
Hubungan Status Pekerjaan dengan Keaktifan Kunjungan Ibu dalam Posyandu di Posyandu X Surabaya
}

\author{
Meivy Isnoviana ${ }^{1 *}$, Jesica Yudit ${ }^{2}$ \\ Bagian Etik dan Humaniora Fakultas Kedokteran ${ }^{1}$ \\ Universitas Wijaya Kusuma Surabaya \\ Fakultas Kedokteran Universitas Wijaya Kusuma Surabaya ${ }^{2}$ \\ *e-mail: pinky7dr@gmail.com
}

\begin{abstract}
Abstrak
Posyandu adalah suatu Upaya Kesehatan Bersumber Daya Masyarakat (UKBM) yang pengelolaan, penyelenggaraannya, dan peruntukkannya oleh masyarakat. Upaya ini akan memantau pertumbuhan serta perkembangan balita setiap bulan. Di Posyandu X Surabaya pada tahun 2018 , hanya $36,75 \%$ balita yang ditimbang dan menunjukkan indikator di bawah cakupan penimbangan balita dengan standar penetapan oleh pemerintah yaitu sebanyak $85 \%$. Tujuan penelitian ini untuk mengetahui hubungan antara status pekerjaan dengan keaktifan kunjungan ibu dalam kegiatan posyandu di Posyandu X Surabaya. Rancangan penelitian adalah penelitian analitik observasional menggunakan pendekatan cross sectional. Populasi adalah seluruh ibu dari bayi dan balita berumur 0 - 59 bulan yang bertempat tinggal di wilayah Posyandu X Surabaya dengan besar sampel 91 responden diambil secara purposive sampling. Data diambil dengan lembar dengan analisis menggunakan uji rank spearman $(\alpha=0,05)$. Hasil penelitian menunjukkan sebagian besar $(47,3 \%)$ ibu dari balita di Posyandu X Surabaya tidak bekerja dan $(50,5 \%)$ menunjukkan keaktifan kunjungan ke posyandu yang jarang. Hasil uji statistik menunjukkan $p$ value $=0,000$ dan $r=0,465$ sehingga terdapat hubungan antara pekerjaan dengan keaktifan kunjungan ibu dari balita dalam kegiatan posyandu di Posyandu $X$ Surabaya. kesimpulannya ibu yang bekerja tidak mempunyai waktu luang berkunjung ke posyandu jika dibandingkan ibu yang tidak bekerja.
\end{abstract}

Kata Kunci: status pekerjaan, keaktifan kunjungan, balita, posyandu

\section{Correlation of Working Status with the Mother's Activity to Visits in Posyandu at Posyandu $X$ Surabaya}

\begin{abstract}
Posyandu is a Community-Based Health Effort (UKBM) which is managed, administered and designated by the community. It will monitor the growth and development of toddlers every month. In the posyandu Surabaya in 2018, only about $36.75 \%$ of toddlers was weighed which is below the indicator of the coverage by Government as $85 \%$. The purpose of this study was to find out the relationship of working status with the mother's activity to visit in posyandu at Posyandu $X$ Surabaya. The study design was observational analytic with a cross sectional approach. The population were mothers with toddlers aged 0 - 59 months who reside in the area of Posyandu with a sample size of 91 respondents taken by purposive sampling. Data collection using questionnaire sheets. Data were analyzed by the Spearman rank test ( $\alpha=0.05)$. The results of the study showed that the majority of toddlers in the Posyandu area (47.3\%) were not working mothers and the activeness of visits to the posyandu were rare (50.5\%).
\end{abstract}


Hubungan Status Pekerjaan dengan Keaktifan Kunjungan Ibu dalam Posyandu di Posyandu X... Meivy Isnoviana, Jesica Yudit

Spearman rank statistical test results obtained $p$ value $=0,000$ and $r=0.465$ means that there is a correlation between working status and the mother's activity of visits in Posyandu activity at Posyandu $X$ Surabaya. It can be concluded that working mothers do not have free time to visit posyandu compared to mothers who do not work

Keywords: mother's working status, activity of visits, posyandu

\section{PENDAHULUAN}

Pemeliharaan kesehatan merupakan salah satu upaya dalam mengurangi angka kesakitan dan kematian anak balita. Anak balita yaitu anak dengan usia satu sampai lima tahun merupakan periode yang disebut golden age. Pertmbuhan dan perkembangan mengalami proses peningkatan pesat di periode ini (Nantabah et al, 2019). Pemeliharaan kesehatan anak dan balita diutamakan kepada upaya pencegahan, peningkatan pelayanan kesehatan dan pengobatan serta rehabilitasi. Pelayanan kesehatan anak dan balita dapat dilaksanakan di puskesmas, puskesmas pembantu, polindes terutama di posyandu. (Syahrir dkk, 2013).

Pos pelayanan terpadu (Posyandu) mejadi suatu bentuk partisipasi masyarakat yang berarti besar bagi kesehatan dan kesejahteraan masyarakat dan merupakan bentuk peran serta masyarakat dalam pembangunan kesehatan dengan sasaran utama pada kelompok bayi, balita, ibu megandung serta wanita usia subur. Pelaksanaan posyandu merupakan salah satu kegiatan untuk menjangkau masyarakat terhadap pelayanan kesehatan primer. Kasus kurang gizi dan gizi buruk sering kali sulit diidentifikasi di masyarakat, ibu yang aktif dalam kunjungannya ke Posyandu bermanfaat dalam pemantauan kesehatan dan gizi anak, yaitu aktif dilakukan penimbangan berat badan rutin (Fitri dan Suminar, 2018). Kejadian malnutrisi memiliki kaitan yang erat dengan pemanfaatan posyandu sebagai pelayanan kesehatan (Sartika, 2010).

Posyandu didirikan dengan tujuan menurunkan angka kematian bayi juga balita, yang pelaksanaannya dilakukan oleh kader kesehatan kompeten yang telah mendapatkan Pendidikan dan pelatihan dari puskesma (Saepudin et al, 2017). Posyandu menjadi sarana bertemu dan kolaborasi antara pelayanan profesional petugas kesehatan dan peran serta masyarakat dalam menanggulangi masalah kesehatan (Utami, dkk, 2016).

Pada tahun 2012 diperkirakan 25\% atau 162 juta anak diseluruh dunia mengalami malnutrisi, sedangkan di Indonesia terdapat $36 \%$ balita yang mengalami malnutrisi, berdasarkan data UNICEF. Gizi kurang merupakan salah satu masalah gizi utama pada balita di 
ISSN 1978-2071 (Print); ISSN 2580-5967 (Online) Jurnal Ilmiah Kedokteran Wijaya Kusuma 9(2) : 112-122, September 2020

Indonesia. Gizi kurang dan gizi buruk mejadi penyebab kematian sekitar 55\% anak balita di Indonesia (Kusumawati dan Rahardjo, 2012). Prevalensi gizi buruk pada amal usia $12-13$ bulan sebesar $9,8 \%$ pada tahun 2000 dan meningkat menjadi 10,9\% pada tahun 2005 (Sartika, 2010). Organisasi Kesehatan Dunia (WHO) menyebutkan bahwa Indonesia merupakan negara dengan status kekurangan gizi yang tinggi karena tingginya angka wasting dan stunting pada tahun 2103, yaitu sebesar $13.5 \%$ untuk wasting dan 36,4\% untuk stunting (WHO, 2014).

Laporan Badan Perencanaan Pembangunan Nasional pada tahun 2010, angka kematian balita sebesar 44/1000 kelahiran hidup pada tahun 2009. Hasil Riskesdes 2010 menunjukkan prevalensi gizi kurang menjadi $17,9 \%$ dan gizi buruk menjadi $4.9 \%$, artinya kemungkinan besar sasaran pada tahun 2014 sebesar 15,0\% untuk gizi kurang dan 3,5\% untuk gizi buruk dapat tercapai (Depkes RI, 2012).

Sasaran Rencana Pembangunan Jangka Menengah Nasional (RPJMN) di tahun 2015-2019 dan sasaran Pembangunan Berkelanjutan (SDGs 2030) adalah prevalensi kekurangan gizi (underweight) pada anak balita 19,6\% pada tahun 2013 menjadi 17\% di tahun 2019. Strategi utama untuk menurunkan prevalensi gizi kurang adalah meningkatkan kegiatan pencegahan melalui pemantauan pertumbuhan anak di Posyandu (Kemenkes $R I, 2012$ ).

Berdasarkan hasil pengambilan data awal di Posyandu $\mathrm{X}$ pada bulan Januari sampai dengan Agustus tahun 2018 menunjukan rata-rata perbulan jumlah seluruh balita (S) 117 balita, ditimbang (D) 43 balita, yang tidak ditimbang (O) 74 balita, yang naik berat badan (N)38 balita, yang turun berat badan (T) 5 balita. Jumlah Kader yang ada di Posyandu 7 orang dan semuanya aktif, di tambah 1 orang bidan untuk membantu dalam pelaksanaan posyandu (Data Posyandu X Surabaya, 2018).

Belum tercapainya apa yang menjadi target SDGs tentang AKB tersebut, ini menunjukan bahwa masih rendahnya derajat kesehatan di Indonesia. Salah satu penyebab adalah karena belum dimanfaatkannya sarana pelayanan kesehatan secara optimal oleh masyarakat, termasuk Posyandu. Menurut L. Green (1980) perilaku kesehatan dalam hal ini kunjungan balita ke posyandu dipengaruhi oleh beberapa faktor antara lain: faktor predisposisi (pengetahuan, pekerjaan, dukungan keluarga), faktor pendukung (diantaranya tersedia atau tidak tersedianya fasilitas kesehatan) dan faktor pendorong yang terwujud dalam sikap dan 
Hubungan Status Pekerjaan dengan Keaktifan Kunjungan Ibu dalam Posyandu di Posyandu X... Meivy Isnoviana, Jesica Yudit

perilaku petugas kesehatan atau petugas lainnya (Notoatmodjo, 2012).

Status gizi seorang balita juga dipengaruhi oleh faktor eksternal berupa penghasilan suatu keluarga, Pendidikan dan pengetahuan, pekerjaan orang tua, jumlah anggota keluarga yang dinafkahi serta pola konsumsi pangan (Nisak, 2018). Pekerjaan yang dilakukan ibu dapat melatar belakangi kurangnya kunjungan ibu balita ke posyandu oleh karena banyaknya pekerjaan sehingga tidak ada waktu untuk membawa balita (Krisnadi, dkk, 2009).

Dalam mengantisipasi hal tersebut promosi kesehatan perlu ditingkatkan dan terus dimasyarakatkan dengan memberikan informasi yang jelas, lengkap dan berkelanjutan tentang posyandu serta perlu dilakukan penyuluhan pada keluarga agar dapat memberikan dukungan dan memotivasi ibu untuk aktif melakukan kunjungan ke posyandu. Mengaktifkan peran kader karena kader merupakan penyelenggara utama dalam kegiatan posyandu. Keikutsertaan kader dalam pelaksanaan kegiatan posyandu diharapkan meningkatkan partisipasi masyarakat untuk membawa balitanya dalam kegiatan posyandu.

Adapun tujuan penelitian ini adalah untuk mengetahui hubungan status pekerjaan dengan keaktifan kunjungan ibu dalam kegiatan posyandu di Posyandu $\mathrm{X}$ Surabaya.

\section{METODE}

Penelitian ini bersifat analitik observasional dengan studi cross sectional. seluruh ibu bayi dan balita umur antara 0 59 bulan yang bertempat tinggal di wilayah Posyandu X Surabaya dengan besar sampel 91 responden diambil secara purposive sampling. Pengumpulan data menggunakan lembar kuesioner, berupa status pekerjaan ibu dan keaktifan dalam kunjungan ke Posyandu. Data dianalisis dengan menggunakan ujii rank spearman dengan tingkat signifikan $\alpha=0,05$. Jika nilai $\mathrm{p}<0,05$ maka $\mathrm{H}_{1}$ diterima berarti ada hubungan pekerjaan dengan keaktifan kunjungan ke posyandu. Penelitian ini dilaksanakan di Posyandu X Surabaya.

\section{HASIL}

\section{Analisis Karakteristik Responden}

Karakteristik responden dalam penelitian ini dapat diamati berdasarkan umur, Pendidikan terakhir, status pekerjaan, dan distirbusi jumlah anak. Untuk distribusi umur, Pendidikan akhir responden dalam hal ini ibu, disajikan pada Tabel 1. 
ISSN 1978-2071 (Print); ISSN 2580-5967 (Online) Jurnal IImiah Kedokteran Wijaya Kusuma 9(2) : 112-122, September 2020

Tabel 1. Distribusi Umur dan Pendidikan Akhir Responden

\begin{tabular}{lccc}
\hline \multicolumn{1}{c}{ Umur } & $\begin{array}{c}\text { Frekuensi } \\
(\%)\end{array}$ & $\begin{array}{c}\text { Pendidikan } \\
\text { terakhir }\end{array}$ & $\begin{array}{c}\text { Frekuensi } \\
(\%)\end{array}$ \\
\hline$<20$ tahun & $12(13,2 \%)$ & SD & $6(6,6 \%)$ \\
$20-30$ tahun & $58(63,7)$ & SMP & $38(41,8 \%)$ \\
$30-40$ tahun & $21(23,1 \%)$ & SMA & $42(46,1 \%)$ \\
$>40$ tahun & $0(0 \%)$ & Perguruan tinggi & $5(5,5 \%)$ \\
\hline Jumlah & $91(100 \%)$ & $91(100 \%)$ \\
\hline \multicolumn{3}{c}{}
\end{tabular}

Tabel 1 menunjukkan bahwa besar pada jenjang SMA sekitar 46,1\% dan sebagian besar (63,7\%) responden jenjang perguruan tinggi menjadi tingkat berumur 20-30 tahun dan sebagian kecil Pendidikan yang paling sedikit yang dimiliki $(13,2 \%)$ responden berumur $<20$ tahun. $\quad(5,5 \%)$. Status pekerjaan ibu dapat dilihat Sedangkan Pendidikan terakhir sebagian pada Tabel 2.

Tabel 2. Distribusi Status Pekerjaan responden

\begin{tabular}{lcc}
\hline \multicolumn{1}{c}{ Pekerjaan } & Frekuensi & Persentase \\
\hline Tidak bekerja & 43 & 47,3 \\
Bekerja dalam rumah & 28 & 30,7 \\
Bekerja luar rumah & 20 & 22 \\
\hline Jumlah & 91 & 100 \\
\hline
\end{tabular}

Sumber: Data Primer 2018

Tabel 2 menunjukkan bahwa sebagian besar $(47,3 \%)$ responden tidak bekerja atau sebagai ibu rumah tangga dan sebagian kecil $(22 \%)$ responden bekerja di luar rumah (PNS, pegawai swasta). Keaktifan kunjungan ibu ke posyandu ditunjukkan frekuensinya pada Tabel 3.

Tabel 3. Distribusi keaktifan kunjungan ke posyandu

\begin{tabular}{lcc}
\hline \multicolumn{1}{c}{ Keaktifan kunjungan } & Frekuensi & Persentase \\
\hline Jarang & 46 & 50,5 \\
Kadang-kadang & 35 & 38,5 \\
Sering & 10 & 11 \\
\hline Jumlah & 91 & 100 \\
\hline
\end{tabular}

Sumber: Data Primer 2018

Tabel 3. dapat diketahui bahwa sebagian besar $(50,5 \%)$ responden jarang melakukan kunjungan ke posyandu dan sebagian kecil (11\%) responden sering melakukan kunjungan ke posyandu. Jumlah anak pada responden dapat dilihat distribusinya pada Tabel 4. 
Hubungan Status Pekerjaan dengan Keaktifan Kunjungan Ibu dalam Posyandu di Posyandu X... Meivy Isnoviana, Jesica Yudit

Tabel 4. Distribusi jumlah anak responden

\begin{tabular}{lcc}
\hline \multicolumn{1}{c}{ Jumlah anak } & Frekuensi & Persentase \\
\hline Primipara (1 anak) & 41 & 45,1 \\
Multipara (2-4 anak) & 50 & 54,9 \\
Grandemulti (>4 anak) & 0 & 0 \\
\hline Jumlah & 91 & 100 \\
\hline
\end{tabular}

Sumber: Data Primer 2018

Tabel 4 menunjukkan bahwa sebagian besar $(59,1 \%)$ responden memiliki 2-4 anak (multipara) dan hampir setengahnya $(45,1 \%)$ responden memiliki 1 anak (primipara).
Hubungan status pekerjaan dengan keaktifan kunjungan ke posyandu

Hubungan Pekerjaan dengan Keaktifan Kunjungan ke Posyandu dapat diamati dengan analisis data rank Spearman seperti yang dapat diamati pada Tabel 5 .

Tabel 5. Hubungan status pekerjaan dengan keaktifan kunjungan ke posyandu

\begin{tabular}{lcccc}
\hline \multirow{2}{*}{ Keaktifan Kunjungan } & \multicolumn{3}{c}{ Pekerjaan } & Jumlah \\
\cline { 2 - 4 } & $\begin{array}{l}\text { Bekerja luar } \\
\text { rumah }\end{array}$ & $\begin{array}{c}\text { Bekerja dlm } \\
\text { rumah }\end{array}$ & Tidak bekerja & $46(100)$ \\
\hline Jarang & $18(39,1)$ & $16(34,8)$ & $12(26,1)$ & $35(100)$ \\
\hline Kadang-kadang & $2(5.7)$ & $8(22,9)$ & $25(71,4$ & $10(100)$ \\
\hline Sering & $0(0)$ & $4(40)$ & $6(60)$ & $91(100)$ \\
\hline Jumlah & $20(22)$ & $28(30,7)$ & $43(47,3)$ & \\
\hline
\end{tabular}

Sumber: Data Primer 2018

Hasil tabulasi silang pada Tabel di atas dapat diketahui bahwa dari 46 responden yang jarang melakukan kunjungan ke posyandu mayoritas $(39,1 \%)$ responden bekerja di luar rumah, sedangkan 35 responden yang kadangkadang melakukan kunjungan ke posyandu sebagian besar $(71,4 \%)$ responden tidak bekerja. Dan 10 responden yang sering melakukan kunjungan ke posyandu sebagian besar (60\%) responden tidak bekerja.

Hasil uji rank spearman didapatkan nilai probabilitas $(p)=0,000$ dengan nilai koefisien korelasi 0,465 . Interval nilai korelasi ( $r$ ) antara 0,26-0,50 adalah korelasi sedang. Dari hasil uji rank spearman didapatkan hasil ada hubungan antara pekerjaan dengan keaktifan kunjungan ibu dalam kegiatan di posyandu X Surabaya, dengan tingkat korelasi sedang.

\section{PEMBAHASAN}

\section{Status Pekerjaan}

Hasil penelitian pada Tabel 2 didapatkan 43 responden (47,3\%) dalam kelompok ibu tidak bekerja (ibu rumah tangga), sedangkan 28 responden $(30,7 \%)$ 
dalam kelompok ibu bekerja dalam rumah (wiraswasta) dan 20 responden (22\%) dalam kelompok ibu bekerja di luar rumah.

Berdasarkan hasil wawancara yang dilakukan peneliti mengatakan bahwa sebagian besar responden mengatakan bekerja untuk mencari nafkah karena untuk membantu suami mereka, sehingga ibu ikut berperan dalam mencari nafkah. Sedangkan ibu yang tidak bekerja atau ibu hanya sebagai seorang ibu rumah tangga yang mengurus anak dan suaminya, sehingga ini menyebabkan ibu tidak bekerja.

\section{Keaktifan kunjungan ibu balita dalam kegiatan posyandu}

Hasil penelitian pada Tabel 3 menunjukkan sebagian besar (50,5\%) responden jarang melakukan kunjungan ke posyandu, $38,5 \%$ responden kadangkadang melakukan kunjungan ke posyandu dan sebagian kecil (11\%) responden sering melakukan kunjungan ke posyandu.

$$
\text { Hasil penelitian ini }
$$

menggambarkan keaktifan kunjungan ibu balita dalam kegiatan posyandu masih rendah dan belum mencapai target pemerintah 85\% (Kemenkes RI, 2015). Sejalan dengan penelitian yang dilakukan di wilayah kerja Puskesmas Pancoran Mas Depok dengan hasil $60,1 \%$ perilaku kunjungan ibu ke Posyandu masih kurang (Purba, 2012).
Posyandu adalah bentuk usaha kesehatan bersumber daya masyarakat (UKBM) dimana kegiatan ini dikelola dan diselenggarakan dari, oleh, untuk dan bersama masyarakat dalam penyelenggaraan pembangunan kesehatan, guna memberdayakan masyarakat dan memberikan kemudahan kepada masyarakat dalam memperoleh pelayanan kesehatan dasar untuk mempercepat penurunan angka kematian ibu dan bayi (Kemenkes, 2011).

Salah satu indikasi pemanfaatan pelayanan kesehatan oleh masyarakat adalah keaktifan kunjungan masyarakat ke pusat pelayanan tersebut dalam hal ini spesfik kepada pemanfaatan pelayanan posyandu yaitu keaktifan orang tua membawa anaknya ke posyandu yang dapat dilihat dari perbandingan diantara jumlah anak yang ditimbang dibandingkan jumlah semua balita yang ada di wilayah tersebut atau $\mathrm{D} / \mathrm{S}$. Perilaku kunjungan pemanfaatan pelayanan kesehatan (posyandu) dipengaruhi oleh beberapa faktor antara lain: umur, pendidikan, pekerjaan, jumlah anak, pengetahuan, sikap, jarak ke posyandu, kepemilikan buku $\mathrm{KIA}$, dukungan keluarga, peran kader dan bimbingan petugas kesehatan (Kemenkes $\mathrm{RI}, 2011)$.

Keaktifan kunjungan ke posyandu juga dipengaruhi faktor jumlah anak dan 
Hubungan Status Pekerjaan dengan Keaktifan Kunjungan Ibu dalam Posyandu di Posyandu X... Meivy Isnoviana, Jesica Yudit

dukungan keluarga. Berdasarkan Tabel 4 menunjukkan sebagian besar (59,1\%) responden memiliki 2-4 anak (multipara). Ibu dengan anak > 1 akan mempunyai waktu atau kesempatan yang kurang untuk mengurus anak dibandingkan dengan ibu yang memiliki anak 1 . Tidak adanya dukungan keluarga terhadap ibu balita akan mempersulit ibu balita dalam melakukan kunjungan ke posyandu, seperti keluarga yang tidak memberikan dukungan emosional, dukungan penghargaan, informasional dan instrumental sehingga mempengaruhi minat ibu balita dalam melakukan kunjungan ke posyandu. Bentuk dukungan keluarga yaitu memberikan informasi dapat berupa sarana pengarahan dan umpan balik tentang bagaimana cara memecahkan masalah antara lain keluarga mengetahui anggota keluarganya yang masih balita, keluarga mengetahui masalah/ penyakit yang biasa terjadi pada balita, keluarga mengetahui sebab-sebab balita rentan terhadap masalah penyakit keluarga mengenali gejala-gejala yang terjadi apabila balita mengalami masalah/ sakit dan keluarga menganggap perawatan pada balita itu penting.

\section{Hubungan pekerjaan dengan keaktifan} kunjungan ke posyandu

Hasil penelitian pada Tabel 5 menunjukkan responden yang jarang melakukan kunjungan ke posyandu mayoritas $(39,1 \%)$ responden bekerja di luar rumah, sedangkan responden yang kadang-kadang melakukan kunjungan ke posyandu sebagian besar (71,4\%) responden tidak bekerja. Dan responden yang sering melakukan kunjungan ke posyandu sebagian besar $(60 \%)$ responden tidak bekerja.

Setelah dilakukan uji statistik rank spearman didapatkan nilai probabilitas $(p)=$ 0,000 dengan nilai koefisien korelasi 0,465 (interval $r$ antara 0,26-0,50 adalah korelasi sedang) berarti ada hubungan antara pekerjaan dengan keaktifan kunjungan ibu balita dalam kegiatan posyandu di Posyandu X Surabaya, dengan kekuatan hubungan yang sedang.

Penelitian ini sejalan dengan penelitian yang dilakukan oleh Rinawati (2014), hasil penelitian menunjukkan bahwa ada hubungan antara status pekerjaan dengan partisipasi ibu balita dalam kegiatan posyandu dengan nilai $(p=0,000)$. Ditegaskan lagi oleh Notoatmodjo (2010), pekerjaan ibu yang dimaksudkan adalah apabila ibu beraktivitas ke luar rumah maupun di dalam rumah kecuali pekerjaan rutin rumah tangga. Peran ibu bekerja yang memiliki balita sebagai timbulnya suatu masalah pada keaktifan kunjungan ibu ke posyandu, karena mereka mencari nafkah untuk memenuhi kebutuhan yang 
berdampak pada tidak adanya waktu para ibu balita untuk aktif pada kunjungan ke posyandu. Tidak adanya cukup waktu dari ibu untuk mencari informasi karena kesibukan mereka dalam bekerja, juga diduga menjadi salah satu penyebab. Hal ini dapat menyebabkan rendahnya frekuensi ibu yang memiliki balita untuk kunjungan ke posyandu akan berkurang.

Dalam penelitian ini diduga status pekerjaan ibu akan berpengaruh terhadap pemanfaatan fasilitas dan sarana kesehatan. Hal tersebut dikarenakan ibu berstatus bekerja akan banyak disibukan dengan aktivitas kesehariannya untuk bekerja, sementara waktu untuk berkunjung dalam mengikuti kegiatan posyandu cukup terbatas. Ibu yang tidak bekerja mempunyai waktu luang lebih banyak untuk berkunjung ke posyandu, setelah mereka menyelesaikan pekerjaan rumah, dan kemungkinan terpapar informasi dari kader kesehatan posyandu akan lebih banyak, sehingga mereka lebih memanfaatkan posyandu dibandingkan ibu yang bekerja.

\section{KESIMPULAN}

Berdasarkan hasil penelitian dan pembahasan yang telah diuraikan maka dapat ditarik simpulan bahwa ada hubungan antara status pekerjaan dan keaktifan kunjungan ibu di Posyandu $\mathrm{X}$.
Sedangkan berdasarkan analisis statistik Rank Spearman didapatkan terdapat hubungan yang sedang antara pekerjaan dengan keaktifan kunjungan ibu balita dalam kegiatan posyandu di Posyandu $\mathrm{X}$ Surabaya.

\section{SARAN}

Berdasarkan hasil penelitian dan pembahasan maka saran yang dapat peneliti berikan adalah sebagai berikut :

1. Masyarakat khususnya ibu balita yang bekerja diharapkan untuk meluangkan waktunya dalam membawa anak balitanya ke posyandu, hal tersebut dapat dilakukan dengan meminta izin di tempat bekerja atau bertukar jadwal dinas ketika waktu penyelenggaraan kegiatan posyandu. Apabila hal tersebut tidak memungkinkan, ibu balita dapat meminta bantuan kepada keluarganya untuk membawa anak balitanya ke posyandu dalam memanfaatkan pelayanan posyandu.

2. Keluarga diharapkan mampu aktif dalam mendukung ibu balita dalam memanfaatkan pelayanan posyandu. Dukungan yang dapat diberikan misalnya mengingatkan jadwal kegiatan posyandu hingga mewakili ibu balita untuk membawa balitanya ke posyandu ketika ibu balita tersebut sedang bekerja atau sebagainya. 
Hubungan Status Pekerjaan dengan Keaktifan Kunjungan Ibu dalam Posyandu di Posyandu X... Meivy Isnoviana, Jesica Yudit

3. Tenaga kesehatan diharapkan memberikan penyuluhan kesehatan yang intensif bagi masyarakat khususnya ibu yang memiliki balita

\section{DAFTAR PUSTAKA}

Depkes RI, 2012. Profil Kesehatan Indonesia. Jakarta: Kemenkes RI.

Fitri F dan Suminar IT, 2018. Posyandu dengan Status Gizi di Desa Pleret Panjatan Kulon Progo. Skripsi. Program Studi IImu Keperawatan Fakultas IImu Kesehatan Universiras 'Aisyiyah Yogyakarta.

Purba EJBR, 2012. Faktor yang berhubungan dengan perilaku kunjungan ke Posyandu pada Ibu Balita di wilayah Kerja Puskesmas Pancoran Mas Kota Depok tahun 2012. Skripsi. Fakultas Kesehatan Masyarakat Universitas Indonesia, Jakarta.

Kemenkes RI, 2011. Pedoman Umum Pengelolaan Posyandu. Jakarta: Kemenkes RI

Kemenkes RI, 2012. Petunjuk pelaksanaan surveilens gizi khusus di kabupaten/ kota. Jakarta: Kemenkes RI

Kemenkes RI, 2015. Pedoman teknis pemantauan status gizi. Jakarta; Kemenkes RI.
Krisnadi SR, Effendi JS, Pribadi A, 2009. Prematuritas. Bandung: Refika Aditama

Kusumawati E dan Rahardjo S, 2012. Pengaruh Pelayanan Kesehatan terhadap Gizi Buruk Anak Usia 624 Bulan. Jurnal Kesehatan Masyarakat Nasional. 6(4): 158162.

Nantabah ZK, Laksnono AD, dan Agustina ZA, 2019. Gambaran Akses Pelayanan Kesehatan pada Balita di Indonesia. https://www.researchgate.net/pu blication/330533001 Gambaran Akses Pelayanan Kesehatan pad a Balita di Indonesia

Nisak NZ, 2018. Hubungan Pekerjaan dan Pengetahuan Gizi Ibu dengan Status Gizi Balita di Desa Duwet Kecamatan Wonosari Kabupaten Klaten. Skripsi. Universitas Muhammadiyah Surakarta.

Notoatmodjo S., 2010. Ilmu Perilaku Kesehatan. Jakarta: Rineka Cipta.

Notoatmodjo S, 2012. Promosi kesehatan dan Perilaku Kesehatan. Jakarta: PT. Rineka Cipta.

Posyandu Bahagia I, 2018. Buku Laporan Kegiatan Bulanan Posyandu Bahagia I. Kedurus Surabaya.

Rinawati, 2014. Faktor-Faktor Yang Berhubungan Dengan Rendahnya 
ISSN 1978-2071 (Print); ISSN 2580-5967 (Online) Jurnal IImiah Kedokteran Wijaya Kusuma 9(2) : 112-122, September 2020

Kunjungan Balita Ke Posyandu Di

Wilayah Kerja Puskesmas

Sukakarya Kota Sabang. Skripsi.

Sekolah Tinggi Ilmu Kesehatan

U’budiyah Program Studi Diploma

IV Kebidanan, Banda Aceh.

Saepudin E, Rizal E, dan Rusman A, 2017.

Peran Posyandu sebagai Pusat

Informasi Kesehatan lbu dan

Anak. Record and Library Journal.

3(2): 201-208.

Sartika RAD, 2010. Analisis Pemanfaatan

Program Pelayanan Kesehatan

Status Gizi Balita. Jurnal

Kesehatan Masyarakat Nasional. 5(2): $76-83$.

Syahrir LM, Fajriansi A, Latief B, 2013. Faktor-faktor yang berhubungan dengan Kunjungan lbu yang

Mempunyai Balita ke Posyandu

Wilayah Kerja Puskesmas

Tamanlarea Makassar. Jurnal

Ilmiah Kesehatan Diagnosis. 2(2):

118-128.

Utami NWA, Adhi KT, Adnyana IMS, 2016.

Pemberdayaan Kader Desa dan

Tokoh Masyarakat dalam

Implementasi Strategi Deteksi Dini

Kasus Malnutrisi Anak Balita di

Desa Bukit Karangasem. Jurnal

Udayana Mengabdi 1.

WHO, 2014. Nutrition Lanscape Information System (NliS).

Department of Nutrition for Health and development (NHD).

Ganeva. 